University of South Carolina

Scholar Commons

\title{
Examining the Role of Churches in Adolescent Girls' Physical Activity
}

Karin A. Pfeiffer

Natalie Colabianchi

Marsha Dowda

University of South Carolina - Columbia, mdowda@mailbox.sc.edu

Dwayne E. Porter

James Hibbert

See next page for additional authors

Follow this and additional works at: https://scholarcommons.sc.edu/

sph_physical_activity_public_health_facpub

Part of the Public Health Commons

\section{Publication Info}

Published in Journal of Physical Activity and Health, Volume 8, Issue 2, 2011, pages 227-233.

Pfeiffer, K., Colabianchi, N., Dowda, M., Porter, D., Hibbert, J., \& Pate, R. R. (2011). Examining the role of churches in adolescent girls' physical activity. Journal of Physical Activity and Health, 8(2), 227-233. (c) Journal of Physical Activity and Health, 2011, Human Kinetics

This Article is brought to you by the Physical Activity and Public Health at Scholar Commons. It has been accepted for inclusion in Faculty Publications by an authorized administrator of Scholar Commons. For more information, please contact digres@mailbox.sc.edu. 


\section{Author(s)}

Karin A. Pfeiffer, Natalie Colabianchi, Marsha Dowda, Dwayne E. Porter, James Hibbert, and Russell R. Pate 


\title{
Examining the Role of Churches in Adolescent Girls' Physical Activity
}

\author{
Karin Pfeiffer, Natalie Colabianchi, Marsha Dowda, Dwayne Porter, \\ James Hibbert, and Russell R. Pate
}

\begin{abstract}
Background: In adults, associations between church attendance and positive health behaviors exist; however, similar evidence among children and youth is lacking. The purposes of this investigation were to examine the associations between physical activity (PA) and church attendance, PA and use of church as a PA facility, and PA and proximity to churches among those who use church as a PA facility (while addressing racial and geographical differences). Methods: High school girls $(\mathrm{N}=915$, age $=17.7 \pm 0.6$ years, $56 \%$ African American) completed the 3-Day Physical Activity Recall and surveys including demographics and use of PA facilities. Geographic Information Systems data were used to spatially examine the number of churches within a 0.75 -mile street network buffer around girls' homes. Associations were examined using mixed model analyses controlling for demographic factors. Results: For the overall sample, total METs (56 versus 52) and proportion of girls meeting PA guidelines ( $62 \%$ vs. 52\%) were significantly higher in church attendees versus nonattendees. Among participants who used facilities, having more churches close to home was associated with more PA. Conclusions: Church attendance and use are correlates of physical activity that should be further explored and addressed in future intervention research with adolescent girls.
\end{abstract}

Keywords: correlates, geographic information systems, built environment

It is well established that girls experience a decline in physical activity during adolescence and that this decline is steeper than the decline that males experience over the same time period. ${ }^{1}$ The benefits of physical activity for children and adolescents are also well-documented; ${ }^{2}$ however, many children and adolescents, especially females, do not meet physical activity recommendations. ${ }^{3}$ In light of this evidence, researchers are continually examining potential correlates of physical activity and methods to increase activity in adolescent females.

One potential correlate of physical activity in adolescent girls is church attendance. There is evidence of associations between church attendance and positive health behaviors in the adult population, particularly among women. ${ }^{4-6}$ Weekly church attendance has been associated with higher odds of walking 5 or more days per week and strenuously exercising 3 or more days per week. ${ }^{7}$ There is less evidence documenting the potential links between church attendance and health behaviors in children and adolescents. Wallace and Forman ${ }^{8}$ reported

Pfeiffer is with the Dept of Kinesiology, Michigan State University, East Lansing, MI. Colabianchi is with the Dept of Epidemiology and Biostatistics, University of South Carolina, Columbia, SC. Dowda and Pate are with the Dept of Exercise Science, University of South Carolina, Columbia, SC. Porter and Hibbert are with the Dept of Environmental Health Sciences, of South Carolina, Columbia, SC. that high school seniors who attended religious services weekly were more likely to be physically active and eat healthy than those who did not attend services. Those who attended religious services weekly were also less likely to engage in substance use and violent behavior than those who did not attend. A positive relationship has also been found between prosocial behaviors such as church attendance and organized sport participation. ${ }^{9}$ The same investigation showed a link between prosocial behaviors and substance use as well; regardless, the existing evidence indicates a positive association between church attendance and physical activity in adolescents.

Little is known about the mechanism by which church attendees may be more physically active. One possible mechanism is through the availability of recreational spaces at and/or organized sports activities through the church. Many churches have a gymnasium and/or a large recreational space as part of their facility, and some churches provide athletic league competition and other types of organized physical activity. Research has shown the availability and proximity of recreational facilities is associated with increased physical activity in both adults and children. ${ }^{10,11}$ For example, in a multicenter trial Cohen et al ${ }^{12}$ showed that the presence of parks was related to physical activity in middle school girls. In another investigation for the same trial, Cohen et $\mathrm{al}^{13}$ found that distance to school and physical activity were inversely related. Thus, it is important to determine the types of recreational facilities available to adolescent 
girls, if girls would use these facilities (given their existence nearby), and if use of the facilities increases physical activity.

To date, churches have not been examined as potential recreational outlets in most studies that examine the availability of physical activity resources and physical activity. Preliminary analyses of our data previously showed that the number of churches within a given distance from girls' residences was significantly related to vigorous physical activity. ${ }^{14}$

In the United States, church attendance is common. In a representative sample of 1200 adults in the United States, $60 \%$ report attending religious services at least once a month, and approximately $44 \%$ attend at least once a week (World Values survey: http://www.worldvaluessurvey.org). It is likely that most adults who attend religious services bring along their children. Available data for high school students show that approximately $58 \%$ of girls and $51 \%$ of boys attend church at least once or twice a month, with $41 \%$ of girls and $35 \%$ of boys attending weekly. ${ }^{15}$ Given that the presence of churches may be related to physical activity in adolescent girls, the church setting could be important for future interventions. Thus, the relationship between churches and physical activity in adolescent girls warrants further investigation.

The purposes of this study were to 1) to examine the associations among physical activity and church attendance in adolescent girls; 2) to examine the association between use of church as a PA facility and physical activity levels; 3 ) to determine if, among girls who use church as PA facility, having a church within a 0.75 mile street network buffer around their home makes them more likely to be active; and 4) to determine if there were any differences in relationships by race/ethnicity and urban/ suburban versus rural areas. All analyses were performed on the overall sample as well as in models stratified by race and urban/rural status.

\section{Methods}

\section{Design}

Cross-sectional data were collected in 2 successive waves of girls as follow-up to a physical activity intervention known as LEAP (Lifestyle Education for Activity Program). ${ }^{16}$ Trained data collectors used standardized procedures and scripts when administering measures to small groups of girls. The study was approved by the University of South Carolina Institutional Review Board. Each participant and parent/guardian (when girls were minors) provided written informed consent/assent.

\section{Subjects}

A total of 5752 girls (42\% African American, 54\% White) in 12 th grade from 22 high schools (urban, suburban, and rural) across the state of South Carolina were invited to participate in the measurement protocol during the spring semester. Of these, 2136 girls gave consent/assent, and 1609 participated in at least some portion of the measurement battery. All girls were not able to complete the full measurement battery due to time constraints imposed on their schedules by the high schools. Every girl completed the physical activity recall and 1 survey regarding correlates of physical activity; girls without time constraints in their schedules also completed 2 additional survey instruments that targeted other correlates of physical activity, including use of facilities for physical activity. The data reported in this paper represent 915 girls (average age $=17.7 \pm 0.6$ years, $56 \%$ African American, BMI 25.2 \pm 6.4) who provided complete data for physical activity, demographic factors, correlates of physical activity, and use of various types of facilities for physical activity.

\section{Physical Activity}

The 3-Day Physical Activity Recall (3DPAR) was used to measure participation in physical activity. In a validity study, ${ }^{17}$ vigorous physical activity (VPA) as measured by the 3DPAR was significantly correlated $(r=.41, P<.001)$ with log transformed VPA measured by accelerometry in 70,8 th and 9 th grade girls $(54.3 \%$ White, $37.1 \%$ African American). The 3DPAR uses a script and graphic figures to explain the intensity of common activities. Light activities are described as requiring little or no movement with slow breathing, moderate activities as requiring some movement and normal breathing, hard activities as requiring moderate movement and increased breathing, and very hard activities as requiring quick movements and hard breathing.

The 3DPAR was always administered on a Wednesday, with girls recalling activities from the immediately preceding Tuesday, Monday, and Sunday. Each day is segmented using a grid format into 30-minute time blocks (7:00 AM to midnight). Participants were asked to report the predominant activity in each of the 30 -minute blocks. A list of 59 activities, grouped into the categories of eating, work, after school/spare time/hobbies, transportation, sleep/bathing, school, and physical activities and sports was provided.

Three physical activity classifications were developed. First, the activities from each block of each day were assigned a MET intensity from the Compendium. ${ }^{18}$ Total physical activity was defined as total METs of activity reported throughout each day (METs/day). Subsequently blocks of moderate-to-vigorous physical activity (MVPA; 3 to 6 METs) and vigorous physical activity (VPA; $\geq 6$ METs) were coded based on the assigned MET values. The girls were then categorized as having on average, 2 or more blocks of MVPA and 1 or more blocks of VPA per day across the 3 days (which is consistent with physical activity guidelines ${ }^{2}$ ) or not. The 3DPAR was also used to classify girls as church attendees or not church attendees. Girls who identified attending church on any of the 3 days included in the 3DPAR were classified as church attendees. 


\section{Surveys}

Girls completed 2 survey instruments aside from the physical activity recall. One survey was used to indicate demographic information, such as age, race (African American or White), and parent education (less than or equal to high school or more than high school). The other survey asked about use of physical activity facilities. A list of 12 types of facilities was provided, and girls indicated if they used each facility or not. Church was included in the list, and girls were considered to use church as a PA facility if they reported yes for church.

\section{Geographic Information Systems Data}

The use of Geographic Information Systems (GIS) allows for spatial examination of places of interest, such as participants' homes. In the present investigation, the addresses of participants' homes were geocoded using GIS-based address matching techniques (ArcView 3.3 software). Church addresses, which were obtained from a variety of sources including internet searches and digital and printed yellow pages, were also geocoded. A count of the number of churches within a 0.75 mile street network buffer around the participant's home was calculated for each participant. The 0.75 mile buffer was chosen because it corresponds to a 15 minute walk, which is considered by older female adolescents to be easy walking distance (assumes that a 3 mile per hour pace would be reasonable). ${ }^{19}$ Urban and suburban classifications were combined to create 1 category, and rural was its own category. The definitions were based on U.S. Census data from the tract where each girl lived. U.S. Census tract data were also used to determine a second indicator of socioeconomic status (in addition to parent education), which was median household income.

\section{Body Mass Index}

Height was measured to the nearest $1.0 \mathrm{~cm}$ with a portable stadiometer, and weight was measured to the nearest 0.1 $\mathrm{kg}$ with a digital scale. The average of 2 trials was used for analysis, and Body Mass Index (BMI) was calculated by dividing weight in kilograms by height in meters squared.

\section{Statistical Analyses}

Both $t$ tests and Chi Square analyses were used to examine and report sample differences. Mixed model analyses were used to explore relationships between PA and church attendance and PA and use of church as a PA facility. Three separate physical activity variables (moderate-to-vigorous (MVPA), vigorous (VPA) and total activity (METs)) were examined. PROC Glimmix (SAS statistical software) was used for the dichotomous outcomes (MVPA, VPA). Any physical activity obtained from working was removed before analysis, since previous examination of the data showed that work was significantly related to physical activity. ${ }^{20}$ Church attendance was a dichotomous variable (yes or no) that reflected if girls reported church on the 3DPAR. Use of church as a physical activity (PA) facility was also a dichotomous variable (yes or no) that reflected answers to a survey regarding use of PA facilities. All models controlled for race, BMI, household income (median household income based on US Census tract data), parent education (dichotomized as high school graduate or less versus greater than high school), and group (intervention vs. control) and had school as a random factor.

Mixed model analysis of variance (ANOVA), controlling for parent education, race, BMI, median house hold income, and intervention versus control status (and treating girls nested within school as a random effect) was also used to determine relationships between number of churches and the total MET measure. The number of churches variable was transformed (square root) due to a skewed distribution.

\section{Results}

The 915 girls included in the present sample were not statistically different than those not included based on race, socioeconomic status, or physical activity (MVPA, VPA); however, the girls in the sample were slightly younger than those not included (17.6 versus 17.7 years old). On average, girls engaged in $53.8(\mathrm{SD}=11.9)$ METS per day of physical activity. Approximately $32 \%$ of participants engaged in 1 or more blocks per day of VPA, and approximately $56 \%$ of participants engaged in 2 or more blocks per day of MVPA. The average body mass index (BMI) of the study's participants was $25.0 \pm$ $6.4 \mathrm{~kg} \cdot \mathrm{m}^{-2}$, and $65 \%$ of the sample had at least 1 parent with greater than a high school education. In addition, median household income was $\$ 41,161 \pm 15,631$.

Half the sample $(50 \%)$ reported church attendance, with a significantly higher proportion of African American girls reporting church attendance than White $(55 \%$ of African American girls attended vs. $44 \%$ of White girls; $P<.01)$. A significantly higher proportion of rural girls $(54 \%)$ reported church attendance than urban/suburban girls $(47 \%, P<.05)$. Overall, $46 \%$ of participants reported that they used church as a PA facility. There was no racial difference in use of church as a PA facility, but there was a difference for urban-suburban/rural, with $51 \%$ of rural girls using church as a PA facility and $43 \%$ of urban/suburban girls using church as a PA facility $(P$ $<.05)$. Of the girls who attended church, $61 \%$ reported that they used church recreational facilities, while $39 \%$ of the girls who did not attend church reported use of church recreational facilities.

Participants had an average of $2.0 \pm 3.7$ churches within a 0.75 -mile radius (street network buffer) of their homes (range $=0$ to 32). African American girls had significantly more churches within the 0.75 -mile radius $(2.4 \pm 4.0)$ than White girls $(1.6 \pm 3.2 ; P<.01)$, but there were no significant differences in number of churches 
between rural and urban/suburban setting (1.9 vs. 2.1, respectively).

Girls who reported church attendance on the 3DPAR reported higher levels of total METs and a higher proportion achieving 2 or more blocks of MVPA than girls who did not report church attendance (Table 1); this was true for the overall sample (56 vs. 52 METs) and urban/ suburban girls $(P<.01)$. African American girls who attended church reported more total METs (55 vs. 49), and higher proportions achieving 2 blocks of MVPA $(55 \%$ vs. $45 \%)$ and 1 or more blocks of VPA (28\% vs., 20\%) than those who did not attend church $(P<.05)$. Among White girls, church attendance was significantly related to attaining 2 or more blocks of MVPA (69\% vs. $60 \% ; P$ $=.05$ ). Rural girls who attended church had significantly higher levels of total METs than rural girls who did not attend church $(56$ vs. $52 ; P<.01)$.
In the overall sample, there was not a significant relationship between PA and use of a church as a PA facility. However for African American girls, those who reported using a church as a PA facility were more likely to report 1 or more blocks of VPA than African American girls who did not use church as a PA facility ( $28 \%$ vs. $21 \%, P=.05$; Table 2).

Finally, among only the girls who reported using church as a PA facility (Table 3 ), there was a significant relationship between number of churches and PA (MVPA, VPA, and total METs). When racial/ethnic and rural versus urban groups were examined separately, African American, White, and rural girls showed significantly greater likelihood of reporting 2 or more blocks of MVPA per day with more churches nearby $(P<.05)$, while rural girls with more churches nearby showed a significant relationship with total METs $(P<.001)$.

Table 1 PA and Church Attendance

\begin{tabular}{|c|c|c|c|c|c|c|c|c|c|c|}
\hline \multirow{3}{*}{$\begin{array}{l}\text { PA variable } \\
\text { (nonwork) }\end{array}$} & \multicolumn{2}{|c|}{ Total $(n=915)$} & \multicolumn{2}{|c|}{$A A(n=516)$} & \multicolumn{2}{|c|}{ White ( $n=399)$} & \multicolumn{2}{|c|}{ Rural $(n=410)$} & \multicolumn{2}{|c|}{$\begin{array}{l}\text { Urban/suburb. } \\
\quad(n=505)\end{array}$} \\
\hline & \multicolumn{2}{|c|}{ Mean (SE) or percent } & \multicolumn{2}{|c|}{ Mean (SE) or percent } & \multicolumn{2}{|c|}{ Mean (SE) or percent } & \multicolumn{2}{|c|}{ Mean (SE) or percent } & \multicolumn{2}{|c|}{ Mean (SE) or percen } \\
\hline & Attend & Do not & Attend & Do not & Attend & Do not & Attend & Do not & Attend & Do not \\
\hline \multirow[t]{2}{*}{ Total METs } & $56.1(0.6)$ & $52.0(0.6)$ & $55.0(0.7)$ & $49.2(0.8)$ & $56.7(1.0)$ & $54.9(0.9)$ & $55.2(1.1)$ & $51.8(1.1)$ & $56.5(0.8)$ & $52.0(0.8)$ \\
\hline & \multicolumn{2}{|c|}{$P<.001$} & \multicolumn{2}{|c|}{$P<.001$} & \multicolumn{2}{|c|}{$P=.14$} & \multicolumn{2}{|c|}{$P<.01$} & \multicolumn{2}{|c|}{$P<.001$} \\
\hline \multirow[t]{2}{*}{ VPA $(\%)$} & $34.3(2.4)$ & $29.1(2.4)$ & $28.0(2.7)$ & $20.2(3.0)$ & $40.4(4.0)$ & $38.8(3.5)$ & $33.6(3.6)$ & $30.4(3.7)$ & $34.2(3.3)$ & $28.3(3.1)$ \\
\hline & \multicolumn{2}{|c|}{$P=.09$} & \multicolumn{2}{|c|}{$P<.05$} & \multicolumn{2}{|c|}{$P=.75$} & \multicolumn{2}{|c|}{$P=.47$} & \multicolumn{2}{|c|}{$P=.16$} \\
\hline \multirow[t]{2}{*}{ MVPA (\%) } & $61.5(2.4)$ & $51.6(2.4)$ & $55.0(3.0)$ & $44.7(3.3)$ & $69.4(3.9)$ & $59.8(3.5)$ & $59.2(3.5)$ & $53.8(3.6)$ & $62.9(3.5)$ & $50.0(3.3)$ \\
\hline & \multicolumn{2}{|c|}{$P<.01$} & \multicolumn{2}{|c|}{$P<.05$} & \multicolumn{2}{|c|}{$P=.05$} & \multicolumn{2}{|c|}{$P=.27$} & \multicolumn{2}{|c|}{$P<.01$} \\
\hline
\end{tabular}

Note. Mixed model analyses controlling for race (when appropriate), BMI, household income, parent education, and group (Intervention, Control) and with school nested in group as a random factor; Attend $=$ attends church, Do not $=$ does not attend church; PA $=$ physical activity, VPA $=$ vigorous physical activity ( $\%$ reporting $\geq 1$ block per day), MVPA = moderate-to-vigorous physical activity (\% reporting $\geq 2$ blocks per day), AA = African American.

Table 2 PA and Use of Church Recreational Facilities

\begin{tabular}{|c|c|c|c|c|c|c|c|c|c|c|}
\hline \multirow[b]{3}{*}{$\begin{array}{l}\text { PA variable } \\
\text { (nonwork) }\end{array}$} & \multicolumn{2}{|c|}{ Total $(n=915)$} & \multicolumn{2}{|c|}{$A A(n=516)$} & \multicolumn{2}{|c|}{ White $(n=399)$} & \multicolumn{2}{|c|}{ Rural $(n=410)$} & \multicolumn{2}{|c|}{$\begin{array}{l}\text { Urban/suburban } \\
(n=505)\end{array}$} \\
\hline & \multicolumn{2}{|c|}{ Mean/percent (SE) } & \multicolumn{2}{|c|}{ Mean/percent (SE) } & \multicolumn{2}{|c|}{ Mean/percent (SE) } & \multicolumn{2}{|c|}{ Mean/percent (SE) } & \multicolumn{2}{|c|}{ Mean/percent (SE) } \\
\hline & Use & $\begin{array}{c}\text { Do not } \\
\text { use }\end{array}$ & Use & $\begin{array}{l}\text { Do not } \\
\text { use }\end{array}$ & Use & $\begin{array}{c}\text { Do not } \\
\text { use }\end{array}$ & Use & $\begin{array}{l}\text { Do not } \\
\text { use }\end{array}$ & Use & $\begin{array}{l}\text { Do not } \\
\text { use }\end{array}$ \\
\hline \multirow[t]{2}{*}{ Total METs } & $54.6(0.6)$ & $53.5(0.6)$ & $51.6(0.8)$ & $53.3(0.8)$ & $55.9(1.0)$ & $55.6(0.9)$ & $54.0(1.1)$ & $53.1(1.1)$ & $54.8(0.9)$ & $53.6(0.8)$ \\
\hline & \multicolumn{2}{|c|}{$P=.18$} & \multicolumn{2}{|c|}{$P=.10$} & \multicolumn{2}{|c|}{$P=.80$} & \multicolumn{2}{|c|}{$P=.43$} & \multicolumn{2}{|c|}{$P=.27$} \\
\hline \multirow[t]{2}{*}{ VPA $(\%)$} & $32.7(2.3)$ & $30.8(2.5)$ & $28.4(2.9)$ & $21.0(2.8)$ & $36.8(4.0)$ & $41.5(3.5)$ & $32.6(3.6)$ & $31.5(3.7)$ & $32.2(3.0)$ & $30.2(3.4)$ \\
\hline & \multicolumn{2}{|c|}{$P=.55$} & \multicolumn{2}{|c|}{$P=.05$} & \multicolumn{2}{|c|}{$P=.34$} & \multicolumn{2}{|c|}{$P=.81$} & \multicolumn{2}{|c|}{$P=.64$} \\
\hline \multirow[t]{2}{*}{ MVPA (\%) } & $58.0(2.3)$ & $55.2(2.5)$ & $53.8(3.2)$ & $47.3(3.3)$ & $63.0(3.9)$ & $64.7(3.5)$ & $54.9(3.5)$ & $58.5(3.6)$ & $60.5(3.6)$ & $52.7(3.2)$ \\
\hline & \multicolumn{2}{|c|}{$P=.41$} & \multicolumn{2}{|c|}{$P=.14$} & \multicolumn{2}{|c|}{$P=.72$} & \multicolumn{2}{|c|}{$P=.46$} & \multicolumn{2}{|c|}{$P=.08$} \\
\hline
\end{tabular}

Note. Mixed model analyses controlling for race (when appropriate), BMI, household income, parent education and group (Intervention, Control) and with school nested in group as a random factor; Use = uses church as a PA facility, Do not use $=$ does not use church as a physical activity facility; PA = physical activity, VPA = vigorous physical activity (\% reporting $\geq 1$ block per day), MVPA = moderate-to-vigorous physical activity (\% reporting $\geq 2$ blocks per day), $\mathrm{AA}=$ African American 
Table 3 Relationship Between PA and Number of Churches in Girls Who Use Church Facilities

\begin{tabular}{|c|c|c|c|c|c|c|c|c|c|c|}
\hline \multirow{3}{*}{$\begin{array}{l}\text { PA } \\
\text { variable } \\
\text { (nonwork) }\end{array}$} & \multicolumn{2}{|c|}{ Total $(n=424)$} & \multicolumn{2}{|c|}{$A A(n=241)$} & \multicolumn{2}{|c|}{ White $(n=183)$} & \multicolumn{2}{|c|}{ Rural $(n=208)$} & \multicolumn{2}{|c|}{$\begin{array}{l}\text { Urban/suburban } \\
(\mathrm{n}=216)\end{array}$} \\
\hline & \multicolumn{2}{|c|}{ Mean (SE) or percent } & \multicolumn{2}{|c|}{ Mean (SE) or percent } & \multicolumn{2}{|c|}{ Mean (SE) or percent } & \multicolumn{2}{|c|}{ Mean (SE) or percent } & \multicolumn{2}{|c|}{ Mean (SE) or percen } \\
\hline & $b$ (SE) & $P$ & $b$ (SE) & $P$ & $b$ (SE) & $\boldsymbol{P}$ & $b$ (SE) & $P$ & $b$ (SE) & $\boldsymbol{P}$ \\
\hline $\begin{array}{l}\text { Total } \\
\text { METs }\end{array}$ & $1.5(0.6)$ & 0.01 & $1.3(0.8)$ & 0.08 & $1.5(0.8)$ & 0.08 & $2.9(13.7)$ & $<0.001$ & $0.1(0.8)$ & 0.87 \\
\hline VPA & $0.2(0.1)$ & 0.05 & $0.1(0.1)$ & 0.37 & $0.2(0.1)$ & 0.25 & $0.2(0.1)$ & 0.08 & $0.1(0.1)$ & 0.35 \\
\hline MVPA & $0.3(0.1)$ & 0.002 & $0.3(0.1)$ & 0.05 & $0.3(0.2)$ & 0.04 & $0.5(0.2)$ & 0.002 & $0.2(0.1)$ & 0.21 \\
\hline
\end{tabular}

Note. Mixed model analyses controlling for race (when appropriate), BMI, household income, parent education and group (Intervention, Control) and with school nested in group as a random factor; PA = physical activity, VPA = vigorous physical activity, MVPA = moderate-to-vigorous physical activity, AA = African American.

\section{Discussion}

The major findings indicate that church attendance was related to physical activity (PA) in adolescent girls. Relationships for church attendance held true for racial/ ethnic and rural/urban-suburban subgroups. A relationship between use of church as a facility and physical activity was found only in African American girls. In addition, among girls who used church as a PA facility, the number of churches within a 0.75 -mile street network buffer of the home was significantly associated with MVPA for the total sample and each subgroup except for urban-suburban.

Previous studies, mostly in adults, have shown that church attendance is related to physical activity, particularly in women. Participants in the previously mentioned Hill et al study ( 1500 male and female adults in Texas) who attended religious services weekly were 1.7 times more likely to walk 5 or more days a week and 1.8 times as likely to participate in strenuous exercise 3 or more days a week than those who did not attend religious services. ${ }^{7}$ Rural African American participants from the Women's Cardiovascular Health Network Project who attended religious services were more than 3 times as likely to participate in physical activity than those who did not attend services. ${ }^{21}$ However, another study of African American women in South Carolina showed that attending religious services was not related to physical activity. The authors noted that over $80 \%$ of the sample consisted of individuals who attended services and attributed these findings to a lack of variability in the sample. ${ }^{22}$ Religious commitment was associated with moderate and vigorous physical activity in a sample of women from Upstate New York. ${ }^{6}$ Similarly, using data from the third National Health and Nutrition Examination Survey (NHANES), Gillum and colleagues ${ }^{23}$ showed that infrequent attendance at religious services was associated with higher prevalence of no leisure-time physical activity $[\mathrm{OR}=1.4$ (1.1-1.9)]; however, there were no significant differences in prevalence of moderate or vigorous leisure-time physical activity between infrequent and frequent attendees after statistical adjustment for demographic variables and health status. With regard to adolescents, Wallace and Forman ${ }^{8}$ reported that high school seniors who attended religious services weekly were more likely to be physically active than those who attended services monthly and rarely. Thus, the findings in the current investigation support the notion from previous studies that church attendance is related to physical activity and provide further evidence that the association exists in adolescent girls as well as adults. The relationships between physical activity and use of church as a PA facility and proximity of churches and physical activity are relatively unexplored outside the context of faith-based interventions. An earlier report of our data showed that the presence of churches was related to vigorous physical activity in adolescent girls. ${ }^{14}$ This study expanded our knowledge by showing that African American girls who used church as a PA facility reported more vigorous physical activity than African American girls who did not use church as a PA facility. Further, of the girls who used church as a PA facility, there were significant relationships between physical activity and number of churches within a 0.75 mile street network buffer for the overall sample and for each subgroup except for the urban-suburban group. These results are not surprising given that adult members of African American churches have indicated that they would like walking programs, sports, aerobics, and resistance training offered as physical activity programs at church. ${ }^{24}$ In addition, PA programs at church were a significant correlate of activity for African American women in a cross-sectional investigation. ${ }^{25}$ Despite the fact that similar evidence is not yet available in children and adolescents, interventions such as Go Girls provide evidence that adolescent girls enjoy physical activity programs offered in religious settings ${ }^{26}$ and could potentially be a targeted site for future intervention studies.

It is important to note that church attendance in the South is much higher than other regions of the country (http://www.gallup.com). Further, church attendance can provide a type of social identity, particularly in regions where more individuals attend church. The associations 
found in this investigation may not hold in areas where church attendance is less common. However, in areas where religion is deemed as important and church attendance is elevated, interventionists could use religious tenets when forming their programs for adolescents, similar to methodology previously used for adults in faith-based investigations.

This study had strengths and limitations that affect the ability to generalize results across all populations. The strengths of this investigation include a large and diverse sample of adolescent girls from 13 counties across the state of South Carolina, which provided the ability to examine racial/ethnic and rural/urban-suburban differences. In addition, the GIS data were comprehensively collected and analyzed, which provides an element that is not available in many existing investigations. Limitations of the study are mostly related to the fact that the study was not strictly aimed at examining church-related variables and that the results apply only to African American and White adolescent girls who are in high school in South Carolina. The 3DPAR instrument has not been validated as an indicator of church attendance; however, its validity in describing activity behaviors is well-documented..$^{17,27}$ It is possible that reporting via activity recall may be subject to less effect from social desirability and could provide more accurate results than directly asking questions regarding church attendance. However, it is also possible that, by virtue of asking about 2 activities over the same time span, the likelihood of finding an association between church attendance and PA was enhanced. In addition, although there was a relationship between PA and proximity of churches found in those girls who used church as a PA facility, it is not known if the girls were using those specific churches found within the 0.75-mile street network buffer. As with any investigation that relies on recall, it is possible that reporting errors occurred. There could be confounding variables we did not examine that could affect associations, and in other regions of the country it is possible that differences in the number of churches in urban/suburban versus rural settings exist (even though there was no difference in this investigation). Beyond this, the fact that South Carolina reports some of the highest rates of church attendance in the country could limit generalizability. Finally, several subgroups were examined, which increased the number of relationships examined, thereby increasing the likelihood of significant findings being due to chance.

In summary, attending church, using church as a PA facility (in African American girls), and having more churches close to home (for those who use church as a facility) were found to be positively related to physical activity in adolescent girls. Taken together, results indicate that church attendance and use of church as a PA facility are correlates of physical activity that should be further explored and possibly addressed in future intervention research, particularly with children and adolescents who live in communities where religion plays an important role in social identity.

\section{Acknowledgments}

This study was funded by NIH R01 HL57775. The authors thank the schools and girls who participated in the study. In addition the authors thank LaVerne Shuler and Janna Borden for their project management and Jo Almeida, John Sirard, and Amy Burghardt for their leadership and expertise in data collection.

\section{References}

1. Kimm SY, Glynn NW, Kriska AM, et al. Decline in physical activity in black girls and white girls during adolescence. N Engl J Med. 2002;347(10):709-715.

2. Strong WB, Malina RM, Blimkie CJ, et al. Evidence based physical activity for school-age youth. J Pediatr. 2005;146(6):732-737.

3. Troiano RP, Berrigan D, Dodd KW, Masse LC, Tilert T, McDowell M. Physical activity in the United States measured by accelerometer. Med Sci Sports Exerc. 2008;40(1):181-188.

4. Strawbridge WJ, Shema SJ, Cohen RD, Kaplan GA. Religious attendance increases survival by improving and maintaining good health behaviors, mental health, and social relationships. Ann Behav Med. 2001;23(1):68-74.

5. Arredondo EM, Elder JP, Ayala GX, Campbell NR. Is church attendance associated with Latinas' health practices and self-reported health? Am J Health Behav. 2005;29(6):502-511.

6. Kim KH, Sobal J. Religion, social support, fat intake and physical activity. Public Health Nutr. 2004;7(6):773-781.

7. Hill TD, Burdette AM, Ellison CG, Musick MA. Religious attendance and the health behaviors of Texas adults. Prev Med. 2006;42(4):309-312.

8. Wallace JM, Jr, Forman TA. Religion's role in promoting health and reducing risk among American youth. Health Educ Behav. 1998;25(6):721-741.

9. Duncan SC, Duncan TE, Strycker LA, Chaumeton NR. Relations between youth antisocial and prosocial activities. J Behav Med. 2002;25(5):425-438.

10. Sallis JF, Bauman A, Pratt M. Environmental and policy interventions to promote physical activity. Am J Prev Med. 1998;15(4):379-397.

11. Sallis JF, Hovell MF, Hofstetter CR, et al. Distance between homes and exercise facilities related to frequency of exercise among San Diego residents. Public Health Rep. 1990;105(2):179-185.

12. Cohen DA, Ashwood JS, Scott MM, et al. Public parks and physical activity among adolescent girls. Pediatrics. 2006;118(5):e1381-e1389.

13. Cohen DA, Ashwood S, Scott M, et al. Proximity to school and physical activity among middle school girls: the Trial of Activity for Adolescent Girls Study. J Phys Act Health. 2006;3(Suppl. 1):S129-S138.

14. Pate RR, Colabianchi N, Porter D, Almeida MJ, Lobelo F, Dowda M. Physical activity and neighborhood resources in high school girls. Am J Prev Med. 2008;34(5):413-419. 
15. Smith C, Faris R, Denton ML, Regnerus M. Mapping American adolescent subjective religiosity and attitudes of alienation toward religion: a research report. Sociol Relig. 2003;64(1):111-133.

16. Pate RR, Ward DS, Saunders RP, Felton G, Dishman RK, Dowda M. Promotion of physical activity among highschool girls: a randomized controlled trial. Am J Public Health. 2005;95(9):1582-1587.

17. Pate RR, Ross R, Dowda M, Trost SG, Sirard JR. Validation of a three-day physical activity recall instrument in female youth. Pediatr Exerc Sci. 2003;15:257-265.

18. Ainsworth BE, Haskell WL, Whitt MC, et al. Compendium of physical activities: an update of activity codes and MET intensities. Med Sci Sports Exerc. 2000;32(9, Suppl):S498-S504.

19. Colabianchi N, Dowda M, Pfeiffer KA, Porter DE, Almeida MJ, Pate RR. Towards an understanding of salient neighborhood boundaries: adolescent reports of an easy walking distance and convenient driving distance. Int $J$ Behav Nutr Phys Act. 2007;4:66.

20. Dowda M, Pfeiffer KA, Dishman RK, Pate RR. Associations among physical activity, health indicators, and employment in 12th grade girls. $J$ Womens Health (Larchmt). 2007;16(9):1331-1339.

21. Eyler AA, Matson-Koffman D, Young DR, et al. Quantitative study of correlates of physical activity in women from diverse racial/ethnic groups: The Women's Cardiovascular Health Network Project-summary and conclusions. Am J Prev Med. 2003;25(3, Suppl 1):93-103.
22. Ainsworth BE, Wilcox S, Thompson WW, Richter DL, Henderson KA. Personal, social, and physical environmental correlates of physical activity in African-American women in South Carolina. Am J Prev Med. 2003;25:23-29.

23. Gillum RF. Frequency of attendance at religious services and leisure-time physical activity in American women and men: the Third National Health and Nutrition Examination Survey. Ann Behav Med. 2006;31(1):30-35.

24. Bopp M, Lattimore D, Wilcox S, et al. Understanding physical activity participation in members of an African American church: a qualitative study. Health Educ Res. 2007;22(6):815-826.

25. Bopp M, Wilcox S, Laken M, et al. Factors associated with physical activity among African-American men and women. Am J Prev Med. 2006;30(4):340-346.

26. Resnicow K, Taylor R, Baskin M, McCarty F. Results of go girls: a weight control program for overweight African-American adolescent females. Obes Res. 2005;13(10):1739-1748.

27. McMurray RG, Ring KB, Treuth MS, et al. Comparison of two approaches to structured physical activity surveys for adolescents. Med Sci Sports Exerc. 2004;36(12):21352143. 